\title{
Predictive value of maternal C-reactive protein for detection of histological chorioamnionitis in women with prelabor rupture of membranes
}

\author{
Naskar A. ${ }^{1}$, Ghosh S. ${ }^{2}$ \\ ${ }^{1}$ Dr. Animesh Naskar, Assistant Professor, Department of Gynecology and Obstetrics, ${ }^{2}$ Dr. Somnath Ghosh, Ex-Medical \\ Officer, Department of Pathology; both authors are affiliated with R.G. Kar Medical College \& Hospital, 1 Khudiram \\ Bose Sarani, Kolkata, West Bengal, India.
}

Corresponding Author: Dr. Somnath Ghosh, Ex-Medical Officer, Department of Pathology, R.G. Kar Medical College \& Hospital, 1 Khudiram Bose Sarani, Kolkata, West Bengal, India. E-mail: drsghosh1998@gmail.com

\begin{abstract}
Introduction: Chorioamnionitis can be considered as an unwanted aftermath of PROM and is capable of causing considerable perinatal morbidity and mortality. It has been a focus of interest in many studies. The ability to predict histological chorioamnionitis is a high priority for Obstetricians managing women with PROM at or after 34 weeks. During the last three decades, CRP has been a useful marker of chorioamnionitis and its dreaded sequel. Materials and Methods: With a specific objective to assess the predictive value of maternal CRP in patients with documented histological chorioamnionitis, 80 patients with high CRP value $(>10 \mathrm{mg} / \mathrm{l})$ with PROM constituted the study group, against a matched control of 84 patients with low CRP value $(<10 \mathrm{mg} / \mathrm{l})$ in our study conducted in a tertiary care center in India. Labor process and management of patients were noted. Follow up was done for the mode of delivery, maternal and neonatal morbidity. Results: Significant correlation was found between high CRP ( $>10 \mathrm{mg} / \mathrm{l})$ and histologically proven chorioamnionitis with a sensitivity of $93 \%$, specificity $80 \%$, positive predictive value $75 \%$, and $\mathrm{P}<0.0001$. Also there is significant correlation between high CRP ( $>10 \mathrm{mg} / \mathrm{l})$ and maternal and neonatal morbidity. Conclusion: CRP is a significant relevant predictor of histological chorioamnionitis, maternal and neonatal morbidity.
\end{abstract}

Key words: Chorioamnionitis, C-reactive protein, Predictive value, Prelabor rupture of membrane

\section{Introduction}

Premature or Prelabor rupture of the membranes (PROM) is defined as rupture of membranes before onset of labor, which is one of the most common complications of pregnancy. It occurs in approximately $8 \%$ of all pregnancies, and it is implicated in more than one third of preterm deliveries [1]. Approximately 5\% of all cases occur at term gestations more than or equal 37 weeks; the other $3 \%$ occur in preterm gestations less than 37 weeks [1].

Therefore, the clinical significance of PROM depends on the gestational age at which it occurs. The etiology of PROM is multifactorial. Changes in maternal enzymes, maturational and mechanical forces, chorioamnionic membrane phospholipid content and collagen disruption, amniotic cell cytokines induced by

Manuscript received: $4^{\text {th }}$ May 2019

Reviewed: $10^{\text {th }}$ May 2019

Author Corrected: $15^{\text {th }}$ May 2019

Accepted for Publication: $20^{\text {th }}$ May 2019 fetal signals, bacterial phospholipases and collagenases play major and interrelated roles [2]. Risk factors of PROM include pervious history of patient, cervicovaginal and intrauterine infections.

Chorioamnionitis is defined as inflammation of the chorioamnionic membranes of the placenta in response to microbial invasion or due to other pathological process. It is prevalent in patients with preterm premature rupture of the membranes (PPROM) and spontaneous preterm birth (birth before 37 weeks gestation). Chorioamnionitis is traditionally defined under two main classifications:

Histologic- based on microscopic evidence of inflammation of the membranes (infiltration of polymorphonuclear leukocytes and other immunocytes, such as macrophages and T cells) [3]. 


\section{Original Research Article}

Clinical- based on clinical manifestations of local and systemic inflammation (fever $>37.5{ }^{\circ} \mathrm{C}$ ), uterine tenderness, abdominal pain, foul smelling vaginal discharge, maternal $(>100$ beats $/ \mathrm{min})$ and fetal tachycardia ( $>160$ beats $/ \mathrm{min})$ and elevated white blood cell count $\left(>15,000\right.$ cells $\left./ \mathrm{mm}^{3}\right)$. More recently the clinical category has been supported by changes in inflammatory biomarker profiles.

Regardless of these standard definitions, understanding chorioamnionitis is challenging as it reflects a heterogeneous group of risk factors, pathways and presentations. Significant ambiguity exists in case definitions and interpretation of histologic evidence, thereby creating difficulty in understanding the prevention of chorioamnionitis. As a result, neither a definitive screening strategy nor specific clinical interventions are available; so that preterm birth and PPROM associated with chorioamnionitis remain major threats to pregnancy. Although chorioamnionitis often occurs in conjunction with inflammation of other gestational tissues, such as decidua (deciduitis), placental villi (villitis), and the umbilical cord (funisitis); our discussion will be limited to the chorioamnionic membranes.

The incidence of histological chorioamnionitis (HCA) is much higher than that of clinically diagnosed infection, and the correlation between these entities is poor [3]. Chorioamnionitis can be easily overlooked and undiagnosed, particularly if histologic examination of placenta is not performed.

C-Reactive Protein (CRP), a $224 \mathrm{KDa}$ residue protein encoded by the CRP gene located on the long arm of first chromosome (1q21-q23) [4]. It is an acute phase reactant synthesized and released by hepatocytes in response to a wide range of acute and chronic inflammatory conditions like bacterial, viral or fungal infections; rheumatic and other chronic inflammatory diseases; malignancy; tissue injury or necrosis [5]. These conditions cause release of interleukins which initiate the synthesis of CRP and fibrinogen by the liver. During the acute phase response, levels of CRP rapidly increase within 2 hours of acute insult, reaching a peak at 48 hours. With resolution of the acute phase response, the level declines with a relatively short halflife. However, an elevated CRP level does not diagnose a specific disease; rather provide support for the presence of an inflammatory disease [5].

The aim of our study is to investigate the predictive value of maternal C-Reactive Protein (CRP) in subclinical chorioamnionitis. The CRP level may be a better predictor of the risk of chorioamnionitis than peripheral WBC counts; especially if the mother has received corticosteroids which may affect the total WBC count for early onset neonatal infection, in routine use in women with prelabor rupture of membrane at or after 34 completed weeks of gestation. Early treatment by antibiotic to mother can reduce the rate of neonatal sepsis.

Specific objective: To detect the correlation between increased maternal CRP and histological chorioamnionitis in women of prelabor rupture of membranes at or after 34 completed weeks of gestation.

\section{Materials and Methods}

Study area: Department of Gynaecology \& Obstetrics and Department of Pathology, R.G. Kar Medical College \& Hospital, 1 Khudiram Bose Sarani, Kolkata04, West Bengal, India

Study population: Pregnant women admitted for prelabor rupture of membranes at or after 34 weeks of gestation.

\section{Exclusion criteria}

1. Pregnant women with less than 34 completed weeks of gestation.

2. Multifoetal pregnancy.

3. Already existing clinically proven infection.

4. Presence of vaginal infection such as candidiasis and trichomoniasis.

5. Gross congenital anomalies including cardiac, renal, pulmonary etc.

6. Those women who received antibiotics before admission.

\section{Study period: One year}

Sample size: Prelabor rupture of membranes occurs in about $8 \%$ of pregnancies; $3 \%$ before and $5 \%$ after 37 weeks of gestation. For the study to have a statistical significance, a minimum 72 women with raised Creactive protein (CRP) was needed. Assuming that $10 \%$ of assigned women's records will not be available for final analysis, we took minimum sample size of 80 women with raised CRP and matched control of 84 women without increased CRP and compared for predictive value of maternal CRP for detection of histological chorioamnionitis. 


\section{Original Research Article}

Study design: It is a cross-sectional study in which following particulars are studied:

1. Estimation of Maternal Serum $\mathrm{C}$ reactive Protein (CRP).

2. Gestational age (weeks of gestation at admission)

3. Maternal clinical assessment for chorioamnionitis

4. Antibiotic prescription at admission.

5. Type of management (Expectant or Active)- Active management is defined as systematic delivery at admission, regardless of gestational age, infections status and medical history. Expectant management is defined as any other management, including close monitoring for infection status.

1. Time since rupture of membranes.

2. Histological examination (microscopic examination) of placenta and fetal membranes.

\section{Study tools}

1. $5 \mathrm{ml}$ sterile disposable syringe with needle for collection of blood sample for estimation of maternal CRP.

2. Clot vial for collection and transport of the sample to the laboratory.

3. Semiautomatic biochemical analyzer for estimation of CRP by immunoturbidometry method.

4. $10 \%$ neutral buffered formalin for preservation and transport of placenta and fetal membranes.

5. Tissue processing equipments and reagents.

6. Paraffin, incubator, hot air oven, microtome, floatation bath with temperature regulator.

7. Hematoxyline and Eosin (H\&E) stains, DPX, cover slips, glass slides for staining and mounting.

8. Binocular microscope for histological examination.

Study technique: After obtaining permission from the institutional ethical committee and written informed consent from the participants, the study was undertaken in joint collaboration of the Departments of Pathology and Gynecology \& Obstetrics in R.G. Kar Medical College and Hospital, a tertiary center in Kolkata, West Bengal, India.

Maternal serum sample was taken at or soon after admission. Antibiotic treatment was started at admission after collection of blood sample for CRP estimation. Ampicillin was administered except in case of penicillin allergy where erythromycin or azithromycin was given.

Women with a clinical infection at admission were not included in the study. Expectant management was continued until 37 weeks, including clinical and laboratory monitoring for infection Expectant management was also adopted at or after 37 weeks for 48 hours after PROM to promote spontaneous onset of labor and vaginal delivery when possible and not contraindicated.

Diagnosis of histological chorioamnionitis was based on microscopic evidence of inflammation (infiltration of polymorphonuclear leukocytes, lymphocytes and macrophages) of the fetal (chorioamnionic) membranes. For the histological analysis of the placenta, tissue sample from placental membranes was fixed in $10 \%$ neutral buffered formalin and embedded in paraffin blocks, sectioned in the microtome and stained with Hematoxylin and Eosin (H\&E).

The pathologist, blinded to the clinical information, performed these examinations and classified acute inflammation as minor, mild, or severe on the basis of the criteria.

The histological analysis of the placenta was standardized before the beginning of the study by developing a common analysis protocol for all fetal membranes.

Data analysis: Statistical analysis was done to detect the correlation between maternal CRP and histological chorioamnionitis using appropriate statistical methods.

\section{Results}

Table-1: Distribution according to age of the patients

\begin{tabular}{|l|c|c|}
\hline \multirow{2}{*}{ Mean age \pm SD } & Study group $(\mathbf{n}=\mathbf{8 0})$ & Control group $(\mathbf{n}=\mathbf{8 4})$ \\
\cline { 2 - 3 } & $23.56 \pm 2.86$ & $23.18 \pm 3.11$ \\
\hline
\end{tabular}

This table compares the study and control group in terms of age. Student $\mathrm{t}$ test applied on data shows: Standard error 0.467; 95\% C.I - 1.303 to 0.543; Test statistic t -0.813 ; Significance level $(\mathrm{P})=0.4172(>0.05)$. 
Original Research Article

Table-2: Distribution of patients according to gravid.

\begin{tabular}{|l|c|c|c|c|c|c|}
\hline & $\begin{array}{c}\text { Study group } \\
(\mathbf{n = 8 0})\end{array}$ & $\begin{array}{c}\text { Control group } \\
(\mathbf{n = 8 4})\end{array}$ & $\mathbf{9 5 \%}$ C.I & Chi-squared & Df & P-value \\
\hline Primigravida & $44(55 \%)$ & $46(54.76 \%)$ & $\begin{array}{c}-2.1 \% \text { to } \\
29.4 \%\end{array}$ & 17.896 & 1 & 0.9567 \\
\hline Multigravida & $36(45 \%)$ & $38(45.24 \%)$ & $\begin{array}{c}-2.1 \% \text { to } \\
29.4 \%\end{array}$ & 17.896 & 1 & 0.9567 \\
\hline
\end{tabular}

This table compares the study and control group in terms of gravida. Chi square test applied on data yields P-value $0.9567(>0.05)$.

Table-3: Distribution of patients according to gestational age.

\begin{tabular}{|c|c|c|c|c|c|c|}
\hline & $\begin{array}{c}\text { Study group } \\
(\mathbf{n = 8 0})\end{array}$ & $\begin{array}{c}\text { Control group } \\
(\mathbf{n = 8 4})\end{array}$ & $\mathbf{9 5 \%}$ C.I & Chi-squared & Df & P-value \\
\hline Below 37 weeks & $48(60 \%)$ & $46(54.76 \%)$ & $\begin{array}{c}-5.9 \% \text { to } \\
39.4 \%\end{array}$ & 5.695 & 1 & 0.5303 \\
\hline Above 37 weeks & $32(40 \%)$ & $38(45.24 \%)$ & $\begin{array}{c}-5.9 \% \text { to } \\
39.4 \%\end{array}$ & 5.695 & 1 & 0.5303 \\
\hline
\end{tabular}

This table compares the study and control group in terms of gestational age. Chi-square test applied on data yields Pvalue $0.5303(>0.05)$.

Table-4: Distribution of patient according to time since rupture of membranes

\begin{tabular}{|c|c|c|c|c|c|c|}
\hline & $\begin{array}{c}\text { Study group } \\
(\mathbf{n = 8 0})\end{array}$ & $\begin{array}{c}\text { Control group } \\
(\mathbf{n = 8 4})\end{array}$ & $\mathbf{9 5 \%}$ C.I & Chi-squared & Df & P-value \\
\hline$<\mathbf{3 6}$ hours & $30(40.3 \%)$ & $44(55 \%)$ & $-2.43 \%$ to $29.1 \%$ & 2.556 & 1 & 0.1099 \\
\hline$>\mathbf{3 6}$ hours & $50(59.7 \%)$ & $40(45 \%)$ & $-2.43 \%$ to $29.1 \%$ & 2.556 & 1 & 0.1099 \\
\hline
\end{tabular}

This table compares the study and control group in terms of time since rupture of membranes. Chi-square test applied on data yields P-value 0.1099 (>0.05).

Table-5: Distribution of patients according to management

\begin{tabular}{|c|c|c|c|c|c|c|}
\hline & $\begin{array}{c}\text { Study group } \\
(\mathbf{n = 8 0})\end{array}$ & $\begin{array}{c}\text { Control group } \\
(\mathbf{n = 8 4})\end{array}$ & $\mathbf{9 5 \%}$ C.I & Chi-squared & Df & P-value \\
\hline Expectant & $40(50 \%)$ & $42(50 \%)$ & $-15.9 \%$ to $15.9 \%$ & 0.0244 & 1 & 0.8759 \\
\hline Active & $40(50 \%)$ & $42(50 \%)$ & $-15.9 \%$ to $15.9 \%$ & 0.0244 & 1 & 0.8759 \\
\hline
\end{tabular}

This table compares the study and control group according to the type of management as defined in study design. Chisquare test applied on data yields P-value $0.8759(>0.05)$.

Table-6: Distribution of patients according to mode of delivery.

\begin{tabular}{|c|c|c|c|c|c|c|}
\hline & $\begin{array}{c}\text { Study group } \\
(\mathbf{n = 8 0})\end{array}$ & $\begin{array}{c}\text { Control group } \\
(\mathbf{n = 8 4 )}\end{array}$ & $\mathbf{9 5 \%}$ C.I & Chi-squared & Df & P-value \\
\hline Normal & $64(80 \%)$ & $64(76.20 \%)$ & $-9.73 \%$ to $17.1 \%$ & 0.159 & 1 & 0.6899 \\
\hline Cesarean & $16(20 \%)$ & $20(23.80 \%)$ & $-9.73 \%$ to $17.1 \%$ & 0.159 & 1 & 0.6899 \\
\hline
\end{tabular}

This table compares the study and control group according to the mode of delivery. Chi-square test applied on data yields P-value $0.6899(>0.05)$. 
Table-7: Distribution of patients according to hospital stay.

\begin{tabular}{|c|c|c|c|c|c|}
\hline $\begin{array}{c}\text { Mean hospital } \\
\text { stay }\end{array}$ & $\begin{array}{c}\text { Study group } \\
(\mathbf{n = 8 0 )}\end{array}$ & $\begin{array}{c}\text { Control group } \\
(\mathbf{n = 8 4 )}\end{array}$ & $\mathbf{9 5 \%}$ C.I & $\begin{array}{c}\text { P-value } \\
\text { Student } \\
\text { t-test }\end{array}$ \\
\cline { 2 - 6 } & $2.9 \pm 1.255$ & $2.1 \pm 1.15$ & -0.6662 to 0.06623 & 0.0310 & -1.618 \\
\hline
\end{tabular}

This table compares the study and control group according to hospital stay. Student $\mathrm{t}$ test applied on data yields Pvalue $0.0310(<0.05)$ which is statistically significant. There is association of high $\mathrm{C}$-reactive protein $(\mathrm{CRP})$ and more hospital stay.

Table-8: Distribution of patients according to neonatal morbidity (early neonatal sepsis, low birth weight, birth asphyxia).

\begin{tabular}{|c|c|c|c|c|c|c|}
\hline $\begin{array}{c}\text { Neonatal } \\
\text { morbidity }\end{array}$ & $\begin{array}{c}\text { Study group } \\
(\mathbf{n = 8 0})\end{array}$ & $\begin{array}{c}\text { Control } \\
\text { group (n=84) }\end{array}$ & $\mathbf{9 5 \%}$ C.I & $\begin{array}{c}\text { Chi- } \\
\text { squared }\end{array}$ & Df & P-value \\
\hline Present & $54(67.5 \%)$ & $10(11.9 \%)$ & $57.264 \%$ to $79.889 \%$ & 62.032 & 1 & 0.0082 \\
\hline Absent & $26(32.5 \%)$ & $74(88.1 \%)$ & $57.264 \%$ to $79.889 \%$ & 62.032 & 1 & 0.0082 \\
\hline
\end{tabular}

This table compares the study and control group according to neonatal morbidity. Chi-square test applied on data yields P-value $0.0082(<0.05)$. There is statistical significance between high CRP and neonatal morbidity.

Table-9: Distribution of patient according to histological chorioamnionitis (HCA).

\begin{tabular}{|c|c|c|c|c|c|c|}
\hline HCA & $\begin{array}{c}\text { Study group } \\
(\mathbf{n = 8 0})\end{array}$ & $\begin{array}{c}\text { Control } \\
\text { group (n=84) }\end{array}$ & $\mathbf{9 5 \%}$ C.I & $\begin{array}{c}\text { Chi- } \\
\text { squared }\end{array}$ & Df & P-value \\
\hline Present & $60(75 \%)$ & $4(4.76 \%)$ & $57.264 \%$ to $79.889 \%$ & 82.032 & 1 & $<0.0001$ \\
\hline Absent & $20(25 \%)$ & $80(95.24 \%)$ & $57.264 \%$ to $79.889 \%$ & 82.032 & 1 & $<0.0001$ \\
\hline
\end{tabular}

This table compares the study and control group according to histological chorioamnionitis. Chi-square test applied on data yields P-value less than 0.0001 . There is statistical significance between high CRP and histological chorioamnionitis (HCA).

- Sensitivity: 93.75\%; Specificity: 80.00\%; Positive predictive value: 75.00\%; Negative predictive value: $95.24 \%$.

- Area under the ROC curve (AUC): 0.802; 95\% Confidence Interval: 0.633 to 0.917 (Figure: 1)

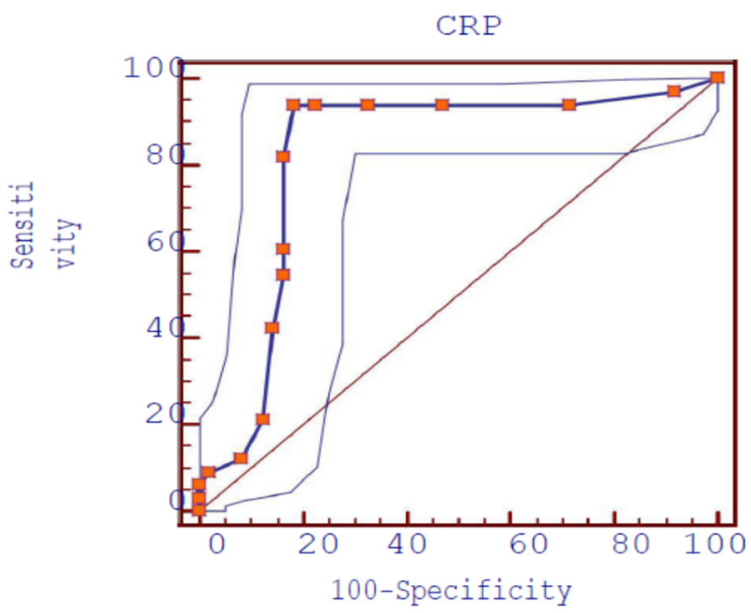

Figure-1: Area under the ROC curve (AUC): 0.802; 95\% Confidence Interval: 0.633 to 0.917 (See Discussion for details) 
Original Research Article

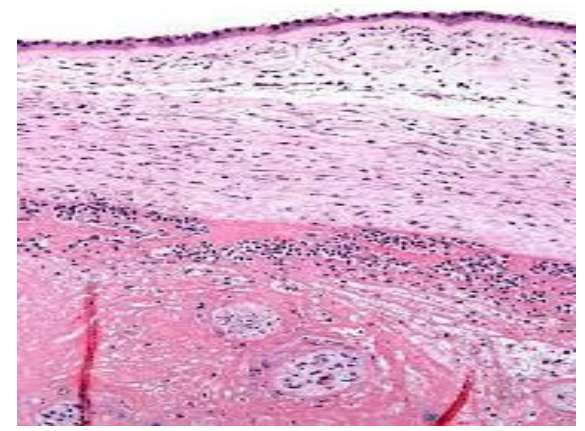

Figure-2: Histological features of chorioamnionitis comprising mixed inflammatory infiltrates consisting of polymorphonuclear leucocytes, eosinophils, lymphocytes and histiocytes admixed with fibrinoid debris, connective tissue edema and evidence of vasculitis (H\&E; 100x)

\section{Discussion}

Histologic chorioamnionitis (Figure-2) captures subclinical as well as clinical chorioamnionitis, thus it is not surprising that overall histologic chorioamnionitis is up to 3 times as frequent as clinical chorioamnionitis confirmed by histology [6]. This is because cultures for genital mycoplasmas, the most common organisms associated with chorioamnionitis, are not very sensitive. Subclinical chorioamnionitis and non-infectious inflammation also contribute to this discrepancy.

Overall, histological chorioamnionitis is a sensitive (83-100\%), but less specific (52\%) predictor of chorioamnionitis than culture positive amniotic fluid [7]. On the other hand, clinical chorioamnionitis is not uniformly confirmed on pathologic evaluation. In a study of 139 pregnancies with clinical findings of chorioamnionitis, histological examination of the placenta did not support the clinical diagnosis in approximately one-third of cases [8]. Hence; placental pathology should be performed to confirm suspected chorioamnionitis even if amniotic fluid culture is negative. Histologic chorioamnionitis is staged on the basis of specific criteria being seen with increasing disease severity [9]:

1) Increasing neutrophil infiltration.

2) The development of necrosis.

3) Amnion basement membrane thickening.

4) Chorionic microabscesses.

In addition, the fetal inflammatory response may progress from chorionic/umbilical vasculitis (neutrophil infiltration in the chorionic or umbilical vessels) to necrotizing funisitis (inflammation of the connective tissue of the umbilical cord). The asymptomatic pregnant mother who presents with premature labor or premature rupture of the membranes may require certain studies to exclude silent chorioamnionitis. To diagnose silent or obvious amniotic fluid infection or chorioamnionitis, the physician often uses laboratory examinations of the amniotic fluid, maternal blood, maternal urine, or a combination to make a diagnosis of infection [10,11]. Although amniocentesis with culture of the amniotic fluid is ideal for isolating bacteria, and is the reference standard for the purpose of diagnosis, this test is associated with a delay of at least 48 hours for cultures, with no evidence of predictive value for potential maternal and neonatal outcomes.

There is also a lack of good-quality trials to demonstrate that this approach reduces either maternal or neonatal morbidity. One study investigated the use of amniocentesis, placental swabs and neonatal skin swabs in the subsequent management of chorioamnionitis following delivery. There was a strong association between positive amniotic cavity culture results and clinical early-onset sepsis; however, there remains insufficient evidence to justify the routine performance or recommendation of amniocentesis for the purposes of diagnosis [12]. The evidence supporting the use of blood cultures for the diagnosis of chorioamnionitis is also limited. It appears that the routine use of maternal blood cultures rarely provides information that justifies a change in clinical management when patients are treated in accordance with a specific antibiotic protocol [13].

Furthermore, there is no good-quality evidence to show the benefit of the use of high vaginal swabs in the diagnosis and management of chorioamnionitis. Several laboratory assessments have been investigated for their potential usefulness in the early prediction and diagnosis of chorioamnionitis. A low vaginal 'pool' amniotic fluid glucose measurement $(<5 \mathrm{mg} / \mathrm{dL})$ was shown to be a predictive but not sensitive marker for 


\section{Original Research Article}

infection in women with PPROM [14]. Similarly, several potential biomarkers of early chorioamnionitis have been identified; including interleukin-6, interleukin-8, C-reactive protein, matrix metalloproteinase-8, ferritin and placental alkaline phosphatase $[15,16]$. The physiological role of CRP is to bind to phosphatidylcholine expressed on the surface of dead or dying cells (and some types of bacteria) in order to activate the complement system and enhance phagocytosis by macrophages $[17,18]$.

Thus CRP participates in the clearance of necrotic and apoptotic cells. It is also believed to play another important role in innate immunity as an early defense system against infections [19]. CRP is used mainly as a marker of inflammation. Blood, usually collected in a serum-separating tube, is analyzed in a medical laboratory or at the point of care. Various analytical methods are available for CRP determination such as ELISA, immunoturbidometry, rapid immunodiffusion, and visual agglutination. A high sensitivity CRP (hsCRP) test measures low levels of CRP using laser nephelometry. In healthy human serum, the level is usually lower than $10 \mathrm{mg} / \mathrm{l}$, slightly increasing with aging [20].

Higher levels may be found in late pregnant women, active inflammation, viral or bacterial infection (40-200 $\mathrm{mg} / \mathrm{l}$ ), and burns. CRP is a more sensitive and accurate reflection of the acute phase response than the ESR. The half-life of CRP is constant. In the first 24 hours ESR may be normal and CRP elevated. CRP returns to normal more quickly than ESR in response to therapy. The use of maternal laboratory markers at or after 34 weeks of gestation would help to distinguish women at risk from those who do not require active management. If infection is confirmed, then termination of that pregnancy becomes vital. Also in women where infection is not present; pregnancy can safely be prolonged.

Their use might make it possible to await spontaneous labor and vaginal delivery and thus avoid caesareans. Prenatal maternal markers of infection at or after 34 weeks have, however, been insufficiently studied. Those that might easily be used in routine care are serum C-reactive protein (CRP) levels, white blood cell counts (WBC count), and bacterial analysis of vaginal samples. No study has included enough women at or after 34 weeks of gestation to allow the predictive values of these markers to be estimated. According to one study, histologic chorioamnionitis (HCA) is associated with preterm delivery and with neonatal morbidity and mortality. Because HCA is usually subclinical, histological examination of the placenta is essential for confirmatory diagnosis. In this study, the correlation between subclinical and histologic chorioamnionitis relevant to clinical and laboratory parameters were analyzed. The results of this study revealed that subclinical HCA was significantly associated with a higher rate of prolonged PROM, lower gestational age, higher maternal WBC count, and elevated CRP level [21].

Another study found no clear evidence to support the use of CRP as an early diagnostic test of chorioamnionitis following PPROM. As with other diagnostic aids, its predictive value has to be weighed in the context of individual clinical situations together with other clinical predictors, bearing in mind the significant risks of intervention or no intervention in response to a false-positive or false-negative result, respectively. Although there is an association between an elevated CRP level and histological chorioamnionitis, the use of commonly accepted CRP thresholds might be misleading. If single measurements were to be used, it would seem appropriate to consider higher cut-off levels of at least $30 \mathrm{mg} / \mathrm{l}$. For serial CRP estimations, levels of $20 \mathrm{mg} / 1$ or above seem predictive of infection.

The use of serial CRP measurements seems promising [22]. However, it is not much recent that a strong association between existence of the histopathological chorioamnionitis and preterm delivery is reported suggesting that occult antepartum infection of the genital tract is an important cause of preterm delivery [23]. It is postulated that the inflammatory response of the host is the first effective factor that influences the events leading to preterm labor and has been a focus of interest in many studies in the region $[24,25,26]$. Some studies have established the participatory role of inflammatory processes as a response to infection [27,28.29]. During the last three decades, CRP has been used by Obstetricians and Gynecologists to identify many inflammatory conditions such as chorioamnionitis. Another study proved CRP to have a diagnostic value in identifying histological chorioamnionitis [30]. This is consistent with previous studies $[31,32,33,34]$.

Our study identified the most reliable parameters for the diagnosis of subclinical chorioamnionitis of the routinely tested prenatal markers. A CRP concentration of $10 \mathrm{mg} / 1$ or more was the most accurate predictor of subclinical chorioamnionitis with a sensitivity of 
$93.75 \%$ and a specificity of $80 \%$. The positive predictive value to determine histological chorioamnionitis is $75 \%$; on the other hand negative predictive value is as high as $95.24 \%$. The association between high CRP in maternal serum and histological chorioamnionitis (subclinical chorioamnionitis) in histopathological examination of placenta is also significant (P-value $<0.0001)$. CRP was associated with histological chorioamnionitis with areas under the receiver operating characteristic curve (ROC) 0.802 with $95 \%$ Confidence Interval 0.633 to 0.917 which means good association between CRP and histological chorioamnionitis.

Other parameter like age of the patient in study group and control group (P-value 0.4172), gravida (Primi/Multi) of the patient (P-value 0.9567 ) in both study and control group are compared but statistical analysis shows they are statistically insignificant in this study. Study population and control population are also compared according to their gestational age ( $>37$ week / $<37$ week), but statistical analysis shows they are statistically insignificant in this study. On the other hand, management of patient in study group and control group are also compared, but statistical analysis shows they are statistically insignificant in this study (P-value 0.8759). Duration of labor and mode of delivery (Vaginal / Cesarean Section) in both groups are comparable, but not significant in this study (P-value 0.6899).

Factors like time since rupture of membrane ( $>36$ hours / $<36$ hours; P-value 0.1099) and gestational age $(>37$ weeks / $<37$ weeks; P-value 0.5303 ) that may create bias for the correlation between maternal CRP and subclinical chorioamnionitis are matched in both study and control group and analyzed statistically, but are found statistically insignificant. Follow up of the patient revealed significantly increased neonatal (P-value 0.0082 ) and maternal morbidity (P-value 0.0310) in study group. One literature supported the stand for predictive value of CRP in case of chorioamnionitis. In addition, they recommended serial measurement of CRP for better accuracy [35].

Another study revealed that CRP was the most reliable indicator of histologic chorioamnionitis and intrauterine infection than WBC or ESR [36]. Another literature concluded that CRP determinations were most reliable with a high sensitivity and specificity [37]. Elevated CRP levels correlated better with pathologic confirmation of chorioamnionitis than the clinical criteria. Also, recent reports indicate that serial CRP levels may be useful for monitoring antibiotic treatment
Our results demonstrate a significant association between HCA with an elevated maternal CRP level in PROM.These findings further confirmed the association between maternal inflammation and preterm deliveries.

\section{Conclusion}

Significant correlation was found between high CRP $(>10 \mathrm{mg} / \mathrm{l})$ and histologically proven chorioamnionitis; also between high CRP $(>10 \mathrm{mg} / \mathrm{l})$ and maternal morbidity (hospital stay) and neonatal morbidity (NICU admission due to early onset of neonatal infection or other associated causes). Hence, CRP is a significant relevant predictor of histological chorioamnionitis, maternal and neonatal morbidity.

Acknowledgement- We are thankful to the Principal and Chairman of the institutional ethical committee to allow us carry out the study in the esteemed institute. We are sincerely grateful to the respective Head of the Departments and support staffs of all units for their valuable inputs and assistance in successfully conducting and finishing the work. There is sufficient contribution of the first author to the overall concept and design of the study, including management of the participants and acquisition of related data. The second author is entrusted with processing and interpretation of histological specimens, quality control of CRP estimation, statistical analysis of the accrued data, manuscript preparation and onward communication. Both the authors have participated significantly to take public responsibility of the appropriate portions of the content.

What this study adds to existing knowledge- Often histological chorioamnionitis is not evidenced clinically. Subclinical chorioamnionitis is associated with early onset neonatal sepsis, which is the most serious consequence of maternal infection and is associated with increased neonatal morbidity and mortality. Accurate prediction of infection, including maternal chorioamnionitis and early onset neonatal infection remains a critical challenge in case of prelabor rupture of membranes and may influence obstetrical management. Numerous studies in recent years have failed to identify a satisfactory maternal marker for subclinical histological chorioamnionitis. The results of our study revealed that subclinical histological chorioamnionitis was significantly associated with a higher rate of prolonged PROM and elevated CRP level in maternal blood. The ability to predict histological chorioamnionitis is a high priority for physicians managing women with PROM as it is the main cause of neonatal morbidity and mortality at or after 34 weeks 


\section{Original Research Article}

We used a pre-specified high sensitivity because the aim of this study was to select a population with a very low risk of infection, who could safely avoid systematic active management. The power of this study is its sample size and variance of patient in our institute. However, a different normal value of CRP at different gestations in pregnancy is to be kept in mind.

Funding: Nil, Conflict of interest: Nil

Permission from IRB: Yes

\section{References}

1. Popowski T, Goffinet F, Maillard F, et al. Maternal markers for detecting early-onset neonatal infection and chorioamnionitis in cases of premature rupture of membranes at or after 34 weeks of gestation: a twocenter prospective study. BMC Pregnancy Childbirth. 2011 Apr 7;11:26. DOI: 10.1186/1471-2393-11-26.

2. Dammann O, Leviton A. Maternal intrauterine infection, cytokines, and brain damage in the preterm newborn. Pediatr Res. 1997 Jul;42(1):1-8.DOI:10. 1203/ 0000 6450-199707000-00001

3. Dong Y, St Clair PJ, Ramzy I, et al. A microbiologic and clinical study of placental inflammation at term. Obstet Gynecol. 1987 Aug;70(2):175-82.

4.Thompson D, Pepys MB, Wood SP.The physiological structure of human C-reactive protein and its complex with phosphocholine. Structure.1999Feb15;7(2):169-77

5. Pepys MB, Hirschfield GM. C-reactive protein: a critical update. J Clin Invest. 2003 Jun 15;111(12): 1805-12. DOI:10.1172/JCI18921

6. Smulian JC, Shen-Schwarz S, Vintzileos AM, et al. Clinical chorioamnionitis and histologic placental inflammation. Obstet Gynecol. 1999 Dec;94(6):1000-5.

7. Pettker CM, Buhimschi IA, Magloire LK, et al. Value of placental microbial evaluation in diagnosing intraamniotic infection. Obstet Gynecol. 2007 Mar;109(3): 739-49. DOI:10.1097/01.AOG.0000255663.47512.23

8. Riggs JW, Blanco JD. Pathophysiology, diagnosis, and management of intraamniotic infection. Semin Perinatol. 1998 Aug;22(4):251-9.

9. Holcroft CJ, Askin FB, Patra A et al. Are histopathologic chorioamnionitis and funisitis associated with metabolic acidosis in the preterm fetus? Am J Obstet Gynecol. 2004 Dec;191(6):2010-5. DOI: 10. 1016/j. ajog.2004.05.005
10. Garite TJ, Freeman RK. Chorioamnionitis in the preterm gestation. Obstet Gynecol. 1982 May;59(5): $539-45$.

11. Tita AT, Andrews WW. Diagnosis and management of clinical chorioamnionitis. Clin Perinatol. 2010 Jun;37 (2):339-54. DOI: 10.1016/j.clp.2010.02.003.

12. Seong HS, Lee SE, Kang JH, et al. The frequency of microbial invasion of the amniotic cavity and histologic chorioamnionitis in women at term with intact membranes in the presence or absence of labor. Am J Obstet Gynecol. 2008 Oct;199(4):375.e1-5. DOI: 10. $1016 / j$. ajog. 2008.06.040.

13. McGregor JA, Schoonmaker JN, Lunt BD, et al. Antibiotic inhibition of bacterially induced fetal membrane weakening. Obstet Gynecol. 1990 Jul;76 (1): 124-8.

14. Buhimschi CS, Sfakianaki AK, Hamar BG et al. A low vaginal "pool" amniotic fluid glucose measurement is a predictive but not a sensitive marker for infection in women with preterm premature rupture of membranes. Am J Obstet Gynecol. 2006, Feb; 194(2): 309-16; DOI: 10.1016/j.ajog.2005.07.070

15. Maeda K, Matsuzaki N, Fuke S, et al. Value of the maternal interleukin 6 level for determination of histologic chorioamnionitis in preterm delivery. Gynecol Obstet Invest. 1997; 43(4):225-31. DOI: 10. $1159 / 000291862$

16. Howman RA, Charles AK, Jacques A, et al. Inflammatory and haematological markers in the maternal, umbilical cord and infant circulation in histological chorioamnionitis. PLoS One. 2012;7(12): e51836. DOI: 10.1371/journal.pone. 0051836. Epub 2012 Dec 13.

17. Tillett WS, Francis T. Serological reactions in pneumonia with a non-protein somatic fraction of pneumococcus. J Exp Med. 1930 Sep 30; 52 (4): $561-71$.

18. Murray RK. Harper's Illustrated Biochemistry. $28^{\text {th }}$ edition. McGraw-Hill Medical. 2009; ISBN: 0-07162591-7

19. Mantovani A, Garlanda C, Doni A, et al. Pentraxins in innate immunity: from C-reactive protein to the long pentraxin PTX3. J Clin Immunol. 2008 Jan; 28 (1):1-13. DOI: $10.1007 / \mathrm{s} 10875-007-9126-7$ 


\section{Original Research Article}

20. McPherson RA, Pincus MR, Henry JB. Henry's Clinical Diagnosis and Management by Laboratory Methods. $21^{\text {st }}$ edition. Philadelphia: Saunders Elsevier, c 2007 ISBN: $9781416002871-1416002871$

21. Wu HC, Shen CM, Wu YY, et al. Subclinical histologic chorioamnionitis and related clinical and laboratory parameters in preterm deliveries. Pediatr Neonatol. 2009 Oct; 50 (5):217-21. DOI: 10.1016/ S1875-9572(09)60066-8.

22. Trochez-Martinez RD, Smith P, Lamont RF Use of $\mathrm{C}$-reactive protein as a predictor of chorioamnionitis in preterm prelabour rupture of membranes: a systematic review. BJOG 2007, Jul; 114(7):796-801; DOI: 10.1111 /j.1471-0528.2007.01385.x

23. Guzick DS, Winn K. The association of chorioamnionitis with preterm delivery. Obstet Gynecol. 1985 Jan;65(1):11-6.

24. Asemi Z, Jazayeri S, Najafi M, et al. Effects of daily consumption of probiotic yoghurt on inflammatory factors in pregnant women: a randomized controlled trial. Pak J Biol Sci. 2011 Apr 15;14(8):476-82.

25. Saeedi M, Veghari GR, Marjani A. Seroepidemiologic evaluation of anti-toxoplasma antibodies among women in north of Iran. Pak J Biol Sci. 2007 Jul 15;10(14):2359-62.

26. Sheikhi A.K, Tayade C, Paffaro V.A et al. Are natural killer cells distributed in relationship to nerve fibers in the pregnant mouse uterus? Pak. J. Biol. Sci. 2007, Sep 1; 10(17): 2885-9

27. Goldenberg RL, Culhane JF, Iams JD, et al. Epidemiology and causes of preterm birth. Lancet. 2008 Jan 5;371(9606):75-84. DOI: 10.1016/S0140-6736(08) 60074-4.

28. Holzman C, Lin X, Senagore P, Chung H. et al. Histologic chorioamnionitis and preterm delivery. Am J Epidemiol. 2007 Oct 1;166(7): 786-94. DOI: 10.1093/ aje/kwm168
29. Hemalatha R., Ramalakshmi B.A., Quadri S.S.Y.H. et al. Intrauterine growth restriction in term women with histologic chorioamnionitis. Res. J. Obstet. Gynecol. 2008, 1(1): 18-24; DOI: 10.3923/rjog.2008.18.24

30. Wiwanitkit V. Maternal C-reactive protein for detection of chorioamnionitis: an appraisal. Infect Dis Obstet Gynecol. 2005 Sep;13(3):179-81. DOI:10.1080/ 10647440500068321.

31. Bańkowska EM, Leibschang J, Pawłowska A. [Usefulness of determination of granulocyte elastase plasma level, c-reactive protein and white blood cell count in prediction in intrauterine infection in pregnant women after PROM]. Ginekol Pol. 2003 Oct;74 (10): 1037-43.

32. Farb HF, Arnesen M, Geistler P, et al. C-reactive protein with premature rupture of membranes and premature labor. Obstet Gynecol. 1983 Jul;62(1):49-51.

33. Kurki T, Teramo K, Ylikorkala O, et al. C-reactive protein in preterm premature rupture of the membranes. Arch Gynecol Obstet. 1990;247(1):31-7.

34. Gojnic M, Fazlagic A, Pervulov M, et al. The significance of C-reactive protein in the diagnosis of fetal tachycardia and therapy of chorioamnionitis. Clin Exp Obstet Gynecol. 2005;32(2):114-6.

35. Fisk NM, Fysh J, Child AG, et al. Is C-reactive protein really useful in preterm premature rupture of the membranes? Br J Obstet Gynaecol. 1987 Dec;94 (12) 1159-64.

36. Nowak M, Oszukowski P, Szpakowski M, et al. [Intrauterine infections. I. The role of C-reactive protein, white blood cell count and erythrocyte sedimentation rate in pregnant women in the detection of intrauterine infection after preliminary rupture of membranes]. Ginekol Pol. 1998 Aug;69(8):615-22.

37. Hawrylyshyn $\mathrm{P}$, Bernstein $\mathrm{P}$, Milligan JE, et al. Premature rupture of membranes: the role of C-reactive protein in the prediction of chorioamnionitis. Am J Obstet Gynecol. 1983 Oct 1;147(3):240-6.

\section{How to cite this article?}

Naskar A, Ghosh S. Predictive value of maternal C-reactive protein for detection of histological chorioamnionitis in women with prelabor rupture of membranes. Obs Rev: J obstet Gynecol 2019;5(2):83-92.doi:10.17511/joog.2019.102.01. 